\title{
FLT3 Inhibitors as Maintenance Therapy Post Hematopoietic Cell Transplantation for Acute Myeloid Leukemia (AML): A Systematic Review and Meta-Analysis
}

\author{
Xinhui Zheng \\ Chinese Academy of Medical Sciences \\ Xiangjun Li \\ Qingdao University \\ Er-Lie Jiang ( $\nabla$ jiangerlie@ihcams.ac.cn ) \\ Chinese Academy of Medical Sciences \\ Liwei Lv \\ Capital Medical University
}

\section{Research Article}

Keywords: Meta-analysis, FLT3 inhibitors, hematopoietic stem cell transplantation, acute myeloid leukemia

Posted Date: December 28th, 2021

DOI: https://doi.org/10.21203/rs.3.rs-1127079/v1

License: (c) (i) This work is licensed under a Creative Commons Attribution 4.0 International License.

Read Full License 


\section{Abstract}

The purpose of this paper is to systematically analyze the outcome of FLT3 inhibitors maintenance treatment following hematopoietic stem cell transplantation (HSCT) for patients suffering from FLT3-ITDmutated acute myeloid leukemia (AML). Pubmed, Embase, and Cochrane Library databases were retrieved before November 2021. Fifteen studies were included eventually containing six without control and nine with control. Thirteen studies evaluated sorafenib, and two assessed quizartinib and midostaurin, separately. Via survival analysis, the main outcomes in the FLT3 inhibitors group were improved greatly with the hazard ratio(HR) of overall survival of 0.38 (95\% confidence interval [Cl], 0.29 0.49 ; $\mathrm{P}<0.001), \mathrm{HR}$ of leukemia-free survival of $0.35(95 \% \mathrm{Cl}, 0.27-0.47 ; \mathrm{P}<0.001)$ and $\mathrm{HR}$ of cumulative incidence of relapse of $0.32(95 \% \mathrm{Cl}, 0.23-0.45 ; \mathrm{P}<0.001)$. Moreover, the TKI use didn't seem to increase the incidence of graft-versus-host disease (GVHD) and adverse effects in statistics. Through subgroup analysis, MRD-positive patients before and after HCT, and MRD-negative patients before HCT might benefit a lot from sorafenib maintenance.

\section{Introduction}

Acute myeloid leukemia (AML) is a heterogeneous clonal hematopoietic stem cell disorder with a poor clinical prognosis and has been considered as the most common acute leukemia affecting adults[1]. The clinical outcome is largely predicted by age, cytogenetics, and specific gene mutations. Traditionally, management options for patients with AML have included chemotherapy, radiotherapy, and immunotherapy. While chemotherapy is still the first-line treatment for AML[2, 3].

Fms-related tyrosine kinase 3 (FLT3) is a class III receptor tyrosine kinase expressed on hematopoietic progenitors and a majority of leukemic myeloblasts $[4,5]$. The internal tandem duplication in the juxta membrane domain of FLT3 (FLT3-ITD) occurring in about 20-25\% of AML leads to constitutive activation of FLT3 and therefore causes a growth advantage to leukemic cells[6] and transformation in cooperation with co-occurring mutations[7]. It is broadly described that among AML patients with FLT3-ITD-positive, only $20 \%$ could achieve stable remission through cytotoxic chemotherapy alone and hematopoietic stem cell transplantation (HSCT) could provide patients the highest likelihood of sustained remission[8-10]. Nevertheless, the relapse rate remains high after treatment [10-13], which suggests that FLT3-ITD is a promising therapeutic target in individualized treatment of AML[14-16]. So much effort has been directed toward developing FLT3 tyrosine kinase inhibitors (TKIs)[2], such as midostaurin, sorafenib, quizartinib, and so on, which have beneficial effects on AML patients demonstrated by current studies[4, 17-19].

Some studies have demonstrated that using TKIs following transplantation might reduce risk of recurrence with associated improvement in survival[20-24]. However, most of them are limited by insufficient sample size and the absence of a control group. Therefore, this research aims at evaluating the impact of TKIs for the post-transplantation treatment of AML patients with FLT3-ITD, focusing on long-term outcomes by comprehensively collecting related clinical studies. 


\section{Materials And Methods \\ 2.1. Search strategy}

Pubmed, Embase, and Cochrane Library entries were retrieved before November 2021 by two investigators. Eligible studies were relevant clinical trials on patients with AML treated with hematopoietic cell transplantation. The search keywords were "FLT3 inhibitors", "AML" and "HSCT" and the search strategy in PubMed was shown in Supplemental strategy.

\subsection{Inclusion and exclusion criteria}

Studies which met the following criteria would be included in this meta-analysis: (1)clinical trials that were published between January 1990 and November 2021, and written in either English or Chinese, (2) studies that described the patients with acute myeloid leukemia and FLT3-ITD mutation undergoing hematopoietic stem cell transplantation, (3) studies that described patients receiving FLT3 inhibitors after transplantation, (4) studies that assessed at least one of the following outcomes: overall survival (OS), relapse-free survival (RFS), the relapse rates, progression-free survival, leukemia-free survival (LFS), nonrelapse mortality (NRM), and cumulative incidence of relapse (CIR). In addition, exclusion criteria were as follows: (1) Preclinical studies, case reports, lectures, commentary, and reviews, (2) Articles without fulltext or a detailed summary of the literature available, (3) Repeatedly published studies, (4) Studies that had no clear endpoint.

\subsection{Quality assessment}

Risk of bias (RoB) for RCTs was assessed using the Cochrane collaborations tool[25]. The NewcastleOttawa quality assessment scale (NOS) was applied to evaluate the quality of non-randomized studies via scoring observational studies on participant selection, comparability of study groups, and ascertainment of exposure or outcome. Studies with scores of six or higher were considered as highquality studies[26]. As to the single-arm studies, retrospective and prospective studies were assessed by the methodological index for non-randomized studies (MINORS)[27] and JBI Critical Appraisal Checklist for Case Series[28].

\subsection{Data extraction}

The following descriptive data were extracted from each included article: the first author's name, year of publication, phase of trials, median age, treatment and dosing regimens, median treatment duration, number of patients available for analysis, and main outcomes. The main outcomes were the hazard ratio (HR) for overall survival (OS, defined as time from inclusion in the study until death. [29, 30]), non-relapse mortality (NRM, the deaths in the absence of persistent relapse[31]), the leukemia-free survival (LFS, the 
survival in a state of continuous complete remission[32]) and cumulative incidence of relapse (CIR, calculated from the date of $\mathrm{CR}$ to the first relapse[33]). If HRs are not available, we calculated them from the available statistics according to Tierney and colleagues[34]. The secondary outcomes were GVHD rates, hematological toxicity, and non-hematological toxicity (gastrointestinal, cardiovascular, biochemical, cutaneous toxicity, infection, and others). GVHD were dichotomized into acute GVHD (either in the first 100 days post-transplant) or chronic GVHD (with manifestations after the first 100 days posttransplant).

\subsection{Statistical analysis}

For data collection, we used Microsoft Excel and statistical analysis was performed using Stata Version 12.0 (Stata Corporation) and Cochrane Review Manager version 5.4 (Cochrane Collaboration). HR of greater than one indicated that the intervention was associated with poor prognosis, while a ratio of less than one meant that it was associated with good prognosis. It was deemed statistically significant if the $95 \%$ credible interval $(\mathrm{Cl})$ did not contain the value of 1 and $P$-values were less than $0.05(P<0.05)$. Heterogeneity among studies was assessed with Cochran's $Q$ test and measured by l-square (I2) statistics. When a P-value $\geq 0.10$, heterogeneity was classified as acceptable. Besides, heterogeneity was classified as low $(12<30 \%)$, moderate $(12 \geq 30 \%)$, substantial $(12 \geq 50 \%)$, or considerable $(12 \geq 75 \%)$. [35]. A random-effects model was selected in the presence of significant heterogeneity; otherwise, a fixed-effect model was preferred[36]. Sensitivity analyses were conducted to examine the impact of single study. Publication bias would be evaluated via a funnel plot and the funnel plot asymmetry could be evaluated through the Egger and Begger's test. A P value more than 0.05 indicated there was no publication bias, whereas publication bias existed. No ethical approval or written, informed consent was required because all analyses were according to previously published data.

\section{Results}

\subsection{Study selection procedure}

The study selection processes are illustrated in Figure 1. First, our initial search yielded 3438 citations from PubMed, Embase, Cochrane. 309 of which were removed due to duplication. By scanning their titles and abstracts, 2970 were excluded due to the following reasons: 2430 studies were not relevant to the subject; 72 studies were in vitro, animal, and other non-clinical studies; 386 studies were other drugs; 23 studies were other diseases; 51 studies were case reports; 35 studies were reviews. Of the 159 full-text studies, 144 studies were deleted because they didn't report the primary outcomes of interest. Therefore, 15 studies were included eventually containing 6 without control[23,37-41] and 9 studies with control comprised of 3 prospective studies $[24,42,43]$ and 6 retrospective studies[22, 44-47].

\subsection{Study Characters}


The characteristics of included studies were presented in Supplemental Table 1.13 studies [22-24, 37, 38, $40,41,43-48]$ used sorafenib, one[39] used quizartinib and one [42]used midostaurin. Four studies[20, 24, $42,47]$ focus on patients with FLT3-ITD AML in first CR. While other studies included patients with FLT3ITD positive AML in first, second, and more hematologic remission (CHR). The dose of sorafenib medication was 200 and $400 \mathrm{mg}$ twice daily for negative and positive MRD separately[49]. While the midostaurin [42, 50]was given 50 mg twice daily in twelve 4-week cycles. And the quizartinib [39] was given 40 and $60 \mathrm{mg}$ daily in the first and second dose levels separately.

\subsection{Prognosis of AML patients post HSCT}

Among the 15 studies, the end points analysis including OS, LFS, CIR, and NRM were conducted for evaluating the clinical effect. The HR of OS extracted from nine articles (eight sorafenib[22, 24, 43-48] and one midostaurin [42] were analyzed with fixed-effect models due to no significant heterogeneity between them $(P=0.63,12=0 \%)$, and the results were shown in a forest plot $(H R=0.38,95 \% \mathrm{Cl}=0.29-0.49$, $P<0.00001$; Figure2.1.1). The pooled HR of LFS from seven articles $[22,24,42-44,46,50]$ was performed using a fixed-effect model $(\mathrm{HR}=0.35,95 \% \mathrm{Cl}=0.27-0.47, \mathrm{P}<0.00001)$, with no heterogeneity observed $(P=0.97$ I2=0\%; Figure 2.1.2). We also calculated the HR of CIR from six articles[22, 24, 43, 44, 46, 48] with no significant heterogeneity $(P=0.96, I 2=0 \%$ Figure 2.1.3) and discovered the result $(H R=0.32,95 \%$ $\mathrm{Cl}=0.23-0.45, \mathrm{P}<0.00001)$ with fixed-effect models. The pooled HR of NRM from five articles[22, 24, 43, $44,46]$ was evaluated using fixed-effect models $(\mathrm{HR}=0.74,95 \% \mathrm{Cl}=0.46-1.19, \mathrm{P}=0.21)$, without heterogeneity between studies ( $P=0.86 \mathrm{I} 2=0 \%$; Figure 2.1.4).

\subsection{Adverse effects}

No significant difference was found for hematological toxic effects, infection, and other nonhematological toxic effects among whether to use sorafenib (Figure 3). Hematological toxic effects were common adverse events including anemia, thrombocytopenia, and neutropenia. The pooled OR of hematological toxic effects from four articles[24, 42-44] was $1.47(95 \% \mathrm{Cl}=0.43-5.09, \mathrm{P}=0.54)$, evaluated by random-effect models with heterogeneity between studies ( $P=0.07 \mathrm{I} 2=58 \%$; Figure 3.1.1). And the OR for gastrointestinal $\square$ cardiovascular $\square$ cutaneous and infectious toxicity was $1.20(95 \% \mathrm{Cl} 0.52-2.81, \mathrm{P}=0.67$; Figure 3.1.1), 1.75(95\% $\mathrm{Cl} 0.50-6.10, \mathrm{P}=0.38$; Figure 3.1.2), 2.52(95\% $\mathrm{Cl} 0.65-9.71, \mathrm{P}=0.18$; Figure 3.1.3), and $1.15(95 \% \mathrm{Cl} 0.65-2.04, \mathrm{P}=0.63$; Figure 3.1 .4$)$ separately.

\subsection{Graft-versus-host disease (GVHD)}

The pooled OR of aGVHD from five articles $[24,42-44,46]$ was 1.00 (95\% $\mathrm{Cl}=0.64-1.54, \mathrm{P}=0.99)$ evaluated by fixed-effect models with none significant differences in heterogeneity. $(P=0.44,12=0 \%$; Figure 4.1.1). As to the pooled $O R$ of $c G V H D$, we acquired the result $(O R=1.30,95 \% \mathrm{Cl}=0.86-1.96, P=0.21)$ from four articles $[24,42-44,46]$ with no significant heterogeneity $(P=0.49,12=0 \%$; Figure 4.1.2). 


\subsection{MRD status before and after HSCT on LFS}

A China study[43] and a Germany study[44] reported the effect of MRD status before and after HSCT on LFS, so that a subgroup analysis was conducted to research it. The HRs of LFS for patients with MRDpositive before HSCT, MRD-negative before HSCT, MRD-positive after HSCT, and MRD- negative after HSCT were (HR=0.48, 95\% $\mathrm{Cl}=0.25-0.95, \mathrm{P}=0.04),(\mathrm{HR}=0.23,95 \% \mathrm{Cl}=0.10-0.52, \mathrm{P}=0.004),(\mathrm{HR}=0.19,95 \%$ $\mathrm{Cl}=0.07-0.54, \mathrm{P}=0.002),(\mathrm{HR}=0.45,95 \% \mathrm{Cl}=0.19-1.03, \mathrm{P}=0.06)$ (Figure 5).

\subsection{Single-arm meta-analysis}

These results were very consistent with those obtained from early researches without control[23, 37-41], in which decreased recurrence and prolonged survival was discovered in our single-arm meta-analysis. As additional supporting evidence, the single-arm meta-analysis was conducted (supplemental Fig. 1-3, available as supplemental material). The pooled rates of 2-year OS, 2-year LFS, 2-year relapse after HSCT with FLT3 inhibitors maintenance were $66 \%$ (95\% Cl, 45-85\%, I2 = 84.15\%; Fig.S1.1), 72\% (95\% Cl, 62$80 \%, I 2=0 \%$; Fig.S1.2), $21 \%(95 \% \mathrm{Cl}, 3-45 \%, \mathrm{I}=69 \%$; Fig.S1.3), separately. The pooled rates of hematological toxic effects, gastrointestinal $\square$ cardiovascular $\square$ cutaneous and biochemical toxicity were $46 \%(95 \% \mathrm{Cl}, 22-74 \%$, I2 = 88.02\%; Fig.S2.1), 24\% (95\% Cl, 15-34\%, I2 = 28.03\%; Fig.S2.2), 12\% (95\% Cl, $3-25 \%, \mathrm{I} 2$ = 67.34\%; Fig.S2.3), 22\% (95\% Cl, 6-42\%, I2 = 80.66\%; Fig.S2.4), 12\% (95\% Cl, 1-28\%, I2 = $77.56 \%$; Fig.S2.5), separately. The pooled rates of aGVHD and cGVHD were $29 \%(95 \% \mathrm{Cl}, 9-53 \%, 12=$ 85.50\%; Fig.S3.1), 20\% (95\% Cl, 2-48\%, I2 = 89.99\%; Fig.S3.2), separately.

\section{Discussion}

AML is an aggressive malignancy with uncontrolled proliferation, impaired differentiation, and increased leukemic blast survival[51]. The FLT3-ITD mutation is the most common mutation in AML, occurs in $25 \%$ of AML patients, and confers a poor prognosis[52]. Despite HSCT therapy, FLT3-ITD mutation have consistently been shown to influence the risk for the relapse and death in AML patients[10]. However, it has not yet been fully elucidated whether FLT3 inhibitors after HSCT further improve the long-term survival of patients with FLT3-ITD, especially in MRD negative or positive.

Apart from studies included, Metzelder suggested this great idea in 2009[52], and further studies had been undertaken to outline the underpinning mechanism in 2012[53]. Sammons' work was also similar and pioneering [54]. The issue of dosage was addressed by Yokoyama [55]. The first case report was done in 2014 by Ahmad Antar with inspiring results [21]. As to the future, Gilteritinib maintenance posttransplantation has been already under investigation in a phase 3 randomized trial (NCT02997202).

Owing to the early retrospective and prospective researches, the results of this meta-analysis show that FLT3 inhibitors' maintenance post-transplantation can improve survival time and prolong recurrence, because compared with the control group, FLT3 inhibitors statistically improve the OS, LFS, and CIR of AML patients. There is no difference for NRM, indicating that the maintenance could extend progression- 
free and overall survival mainly through reducing recurrence. What's more, little difference in the occurrence rates of adverse reactions and GVHD is seen between the two treatment methods, which illustrated that sorafenib maintenance post-transplantation won't worsen immune rejection.

Next, some studies included or not have done some subgroup analysis about age, and mutation detection therapy, and so on. These results need more attention to be paid. Schlenk[50] concluded that midostaurin maintenance therapy benefited not only the young (18-60 years) but also the older people (61-70 years). Tarlock[40] showed relatively better results for pediatric patients, although lamentedly, it lacked the control group. Sandmaier's study[39] exhibited no prominent difference in OS between $40 \mathrm{mg}$ or $60 \mathrm{mg}$ quizartinib treatment groups. Yi-Bin Chen[41]showed that patients who were in a conventional complete remission (CR1/CR2) before HSCT seemed to have better survival. Burchert[44] made an interesting conclusion that the greatest benefit from sorafenib maintenance was demonstrated in MRD-negative patients before HCT and MRD-positive patients after HCT. Maziarz[42] showed that higher P-FLT3 levels indicated less effective FLT3 inhibition. Xuan Li[22, 43] compared the sorafenib effects before and after HSCT and analyzed the effects of gender, age, white blood cell count at diagnosis, cytogenetic risk, NPM mutation, sorafenib pre-transplantation, disease and CRc status at transplantation, MRD at transplantation and post-transplantation and transplant modality. It was interesting that some of the results were contradictory.

After analyzing the effect of MRD status before and after HSCT on LFS in two studies[43, 44], it was concluded that MRD-positive patients before and after HCT, and MRD-negative patients before HCT might benefit a lot from sorafenib maintenance. MRD-negative patients after HCT seemed to have better survival owing to sorafenib maintenance, although this was not statistically significant. Considering the fact that sample quantity was relatively small, the persuasiveness of the results was limited. However, the number of subgroups was too small to be merged. Therefore, more subgroup analyses were expected in the following factors: age, CRc status at transplantation, P-FLT3 levels, cytogenetic risk, MRD at transplantation, and transplant modality.

As in the previous study[43], no statistical difference in GVHD was noted between the two groups, which might indicate FLT3 Inhibitors played a role through other mechanisms rather than just potentiating antitumor T cell responses.

As to safety, regrettably, the only one quizartinib[39] study is without control and only 13 patients were incorporated. It's a pity that the midostaurin study by Schlenk [50] wasn't suitable to be incorporated so that only selected midostaurin study by Maziarz [42] showed not so persuasive evidence that diarrhea ( $13 \%$ vs $7 \%$ ), nausea and vomiting ( $3 \%$ vs $10 \%$ ), and pyrexia (7\%vs $7 \%$ ) (midostaurin arm vs SOC arm). As to sorafenib, the incidence of cardiovascular and skin toxicity seemed to be slightly increased in the sorafenib group, but this difference did not achieve statistical significance. Moreover, differentiation in skin rashes caused by sorafenib or GVHD has always been a difficulty in clinical diagnosis.

Compared with earlier published meta-analyses [52], the effect of variables (OS, CIR, LFS, and NRM) changes over time on outcome measures was considered since survival analyses has been performed, 
which was the main reason for this "repeated" analysis. It was also worth mentioning that the study lent support to the use of the FLT3 inhibitors as a maintenance treatment for MRD-negative patients before HSCT. What's more, as a supplementary for RCTs, 4 prospective or 2 retrospective studies without control were included for single-arm meta-analysis. Last but not least, compared with Nico Gagelmann's study [52], 3 more sorafenib studies were added and 1 midostaurin study was excluded because the study lacked a control group, and some patients incorporated were treated with high-dose cytarabine (HiDAC) after consolidation instead of HSCT. Because of the difference in included studies and statistical methods, more comprehensive and powerful evidence was provided and the conclusion was actually different from the earlier research.

Although numerous strengths exist, there are also some study limitations. First, the number of included studies was low, especially in the quizartinib and midostaurin groups. To understand which FLT3 inhibitors are better, further studies are needed. Further research is needed to ascertain which for posttransplantation maintenance for FLT3-ITD acute myeloid leukaemia. Second, after evaluating the quality of articles, it is found that 2 correspondences[46, 48], 1 letter[47], and 1 oral presentation[45] are of low quality and 1 prospective study [44] was terminated early because of slow recruitment, which may lead to some limitations of this study. Third, age groups, the conditioning protocol and intensity, and the FLT3 inhibitors' actual dose, timing, and duration were indeed different. Fourth, though better than logistic regression, the survival analysis needs to consider the time of every patient for entry and there may be a

degree of error in the HR data because several HRs could not be rapidly obtained in articles and had to be calculated from the Kaplan-Meier survival curves, potentially leading to bias.. Last, some variables are more likely to affect survival and relapse, such as age, CRc status, P-FLT3 levels, cytogenetic risk, MRD. It's a pity that relevant studies are so few and there is a need for it to be further explored.

\section{Conclusion}

In general, through survival analysis, the HR of OS, LFS, and CIR after post-transplant TKI therapy in FLT3ITD mutated AML was improved greatly. And the sorafenib use doesn't seem to increase the incidence of GVHD and adverse effects, but more evidence is still be needed. TKI type, age, CRc status, P-FLT3 levels, cytogenetic risk, and MRD may be a cue for the advanced research in the sorafenib effect and more subgroups are expected.

\section{Declarations}

\section{Ethics approval and consent to participate}

Not applicable.

\section{Consent for publication}

Not applicable. 
Availability of data and materials

All data generated or analysed during this study are included in this published article and its supplementary information files.

\section{Competing interests}

The authors reported no conflict of interest.

\section{Funding}

The datasets used and/or analysed during the current study are available from the corresponding author on reasonable request.

\section{Authors' contributions}

All authors read and approved the final version of the manuscript. Xinhui Zheng contributed to the conception of the study, analysis and manuscript preparation. Xiangjun Li performed the data analyses. Liwei Lv and Dr Jiang helped perform the analysis with constructive discussions.

\section{Acknowledgements}

We thank the comments provided by Mr. Ji and Mr. Liu which helped improve the paper.

\section{Authors' information (optional)}

Xinhui Zheng1, Xiangjun Li 2, Liwei Iv 3, Erlie Jiang1

Xinhui Zheng and Liwei Iv contributed equally to this work as first authors.

1 Hematopoietic Stem Cell Transplantation Center, Institute of Hematology and Blood Diseases Hospital, Peking Union Medical College and Chinese Academy of Medical Sciences, Tianjin 300020, China, Tianjin, PR China

2 Qingdao University, Qingdao, China

3 Department of Hematology, Beijing Tiantan Hospital, Capital Medical University, Beijing, China,

Address for correspondence: Dr. Er-Lie Jiang, Hematopoietic Stem Cell Transplantation Center, Institute of Hematology and Blood Diseases Hospital, Peking Union Medical College and Chinese Academy of Medical Sciences, Tianjin 300020, China E-Mail: moc.361@eilregnaij

\section{Reference}


1. Löwenberg, B., J.R. Downing, and A. Burnett, Acute myeloid leukemia. The New England journal of medicine, 1999. 341(14): p. 1051-1062.

2. Döhner, H., et al., Diagnosis and management of acute myeloid leukemia in adults: recommendations from an international expert panel, on behalf of the European LeukemiaNet. Blood, 2010. 115(3): p. 453-474.

3. Milligan, D.W., et al., Guidelines on the management of acute myeloid leukaemia in adults. British journal of haematology, 2006. 135(4): p. 450-474.

4. Hospital, M.-A., et al., FLT3 inhibitors: clinical potential in acute myeloid leukemia. OncoTargets and therapy, 2017. 10: p. 607-615.

5. Meshinchi, S. and F.R. Appelbaum, Structural and functional alterations of FLT3 in acute myeloid leukemia. Clinical cancer research : an official journal of the American Association for Cancer Research, 2009. 15(13): p. 4263-4269.

6. Lee, B.H., et al., FLT3 mutations confer enhanced proliferation and survival properties to multipotent progenitors in a murine model of chronic myelomonocytic leukemia. Cancer Cell, 2007. 12(4): p. 36780.

7. Shih, A.H., et al., Mutational cooperativity linked to combinatorial epigenetic gain of function in acute myeloid leukemia. Cancer Cell, 2015. 27(4): p. 502-15.

8. Lin, P.H., et al., Prognostic impact of allogeneic hematopoietic stem cell transplantation for acute myeloid leukemia patients with internal tandem duplication of FLT3. Leuk Res, 2013. 37(3): p. 28792.

9. DeZern, A.E., et al., Role of allogeneic transplantation for FLT3/ITD acute myeloid leukemia: outcomes from 133 consecutive newly diagnosed patients from a single institution. Biol Blood Marrow Transplant, 2011. 17(9): p. 1404-9.

10. Brunet, S., et al., Impact of FLT3 internal tandem duplication on the outcome of related and unrelated hematopoietic transplantation for adult acute myeloid leukemia in first remission: a retrospective analysis. J Clin Oncol, 2012. 30(7): p. 735-41.

11. Gale, R.E., et al., No evidence that FLT3 status should be considered as an indicator for transplantation in acute myeloid leukemia (AML): an analysis of 1135 patients, excluding acute promyelocytic leukemia, from the UK MRC AML 10 and 12 trials. Blood, 2005. 106(10): p. 3658-65.

12. Deol, A., et al., Does FLT3 mutation impact survival after hematopoietic stem cell transplantation for acute myeloid leukemia? A Center for International Blood and Marrow Transplant Research (CIBMTR) analysis. Cancer, 2016. 122(19): p. 3005-3014.

13. Song, Y., et al., FLT3 mutational status is an independent risk factor for adverse outcomes after allogeneic transplantation in AML. Bone Marrow Transplant, 2016. 51(4): p. 511-520.

14. Kiyoi, H., M. Yanada, and K. Ozekia, Clinical significance of FLT3 in leukemia. Int J Hematol, 2005. 82(2): p. 85-92.

15. Nakao, M., et al., Internal tandem duplication of the ftt3 gene found in acute myeloid leukemia. Leukemia, 1996. 10(12): p. 1911-8. 
16. Sheikhha, M.H., et al., Prognostic significance of FLT3 ITD and D835 mutations in AML patients. Hematol J, 2003. 4(1): p. 41-6.

17. Serve, H., et al., Sorafenib in combination with intensive chemotherapy in elderly patients with acute myeloid leukemia: results from a randomized, placebo-controlled trial. J Clin Oncol, 2013. 31(25): p. 3110-8.

18. Röllig, C., et al., Addition of sorafenib versus placebo to standard therapy in patients aged 60 years or younger with newly diagnosed acute myeloid leukaemia (SORAML): a multicentre, phase 2, randomised controlled trial. Lancet Oncol, 2015. 16(16): p. 1691-9.

19. Hassanein, M., et al., FLT3 Inhibitors for Treating Acute Myeloid Leukemia. Clin Lymphoma Myeloma Leuk, 2016. 16(10): p. 543-549.

20. Battipaglia, G., et al., Efficacy and Feasibility of Sorafenib as a Maintenance Agent After Allogeneic Hematopoietic Stem Cell Transplantation for Fms-like Tyrosine Kinase 3 Mutated Acute Myeloid Leukemia: An Update. Clin Lymphoma Myeloma Leuk, 2019. 19(8): p. 506-508.

21. Antar, A., et al., Sorafenib Maintenance Appears Safe and Improves Clinical Outcomes in FLT3-ITD Acute Myeloid Leukemia After Allogeneic Hematopoietic Cell Transplantation. Clin Lymphoma Myeloma Leuk, 2015. 15(5): p. 298-302.

22. Xuan, L., et al., Effect of sorafenib on the outcomes of patients with FLT3-ITD acute myeloid leukemia undergoing allogeneic hematopoietic stem cell transplantation. Cancer, 2018. 124(9): p. 1954-1963.

23. Battipaglia, G., et al., Efficacy and feasibility of sorafenib as a maintenance agent after allogeneic hematopoietic stem cell transplantation for Fms-like tyrosine kinase 3-mutated acute myeloid leukemia. Cancer, 2017. 123(15): p. 2867-2874.

24. Brunner, A.M., et al., Haematopoietic cell transplantation with and without sorafenib maintenance for patients with FLT3-ITD acute myeloid leukaemia in first complete remission. Br J Haematol, 2016. 175(3): p. 496-504.

25. Julian PT Higgins, J.S., Matthew J Page, Roy G Elbers, Jonathan AC Sterne. Cochrane Handbook for Systematic Reviews of Interventions Chapter 8: Assessing risk of bias in a randomized trial. 2021 2021; Available from: https://training.cochrane.org/handbook/current/chapter-08.

26. Wells GA, S.B., O'Connell D, Peterson J, Welch V, Losos M, et al. . The Newcastle-Ottawa Scale (NOS) for assessing the quality of non randomised studies in meta-analyses. Ottawa: Ottawa Hospital Research Institute. 2009 2021; Available from: https://jbi-global-wiki.refined.site/space/MANUAL.

27. Slim, K., et al., Methodological index for non-randomized studies (minors): development and validation of a new instrument. ANZ J Surg, 2003. 73(9): p. 712-6.

28. Moola S, M.Z., Tufanaru C, Aromataris E, Sears K, Sfetcu R, Currie M, Lisy K, Qureshi R, Mattis P, Mu P. Chapter 7: Systematic reviews of etiology and risk., Joanna Briggs Institute Reviewer's Manual. Chapter 7: Systematic reviews of etiology and risk. 2020.

29. Wagner, K., et al., Impact of IDH1 R132 mutations and an IDH1 single nucleotide polymorphism in cytogenetically normal acute myeloid leukemia: SNP rs 11554137 is an adverse prognostic factor. $\mathrm{J}$ 
Clin Oncol, 2010. 28(14): p. 2356-64.

30. Schnittger, S., et al., IDH1 mutations are detected in 6.6\% of 1414 AML patients and are associated with intermediate risk karyotype and unfavorable prognosis in adults younger than 60 years and unmutated NPM1 status. Blood, 2010. 116(25): p. 5486-96.

31. Kuwatsuka, Y., et al., Phase II study of dose-modified busulfan by real-time targeting in allogeneic hematopoietic stem cell transplantation for myeloid malignancy. Cancer Sci, 2012. 103(9): p. 168894.

32. Craddock, C., et al., Estimating leukemia-free survival after allografting for chronic myeloid leukemia: a new method that takes into account patients who relapse and are restored to complete remission. Blood, 2000. 96(1): p. 86-90.

33. Coenen, E.A., et al., Prognostic significance of additional cytogenetic aberrations in 733 de novo pediatric 11q23/MLL-rearranged AML patients: results of an international study. Blood, 2011. 117(26): p. 7102-11.

34. Tierney, J.F., et al., Practical methods for incorporating summary time-to-event data into metaanalysis. Trials, 2007. 8: p. 16.

35. Guyatt, G.H., et al., GRADE guidelines: 7. Rating the quality of evidence-inconsistency. J Clin Epidemiol, 2011. 64(12): p. 1294-302.

36. DerSimonian, R. and N. Laird, Meta-analysis in clinical trials. Control Clin Trials, 1986. 7(3): p. $177-88$.

37. Metzelder, S.K., et al., Long-term survival of sorafenib-treated FLT3-ITD-positive acute myeloid leukaemia patients relapsing after allogeneic stem cell transplantation. Eur J Cancer, 2017. 86: p. 233-239.

38. Pratz, K.W., et al., A Prospective Study of Peritransplant Sorafenib for Patients with FLT3-ITD Acute Myeloid Leukemia Undergoing Allogeneic Transplantation. Biol Blood Marrow Transplant, 2020. 26(2): p. 300-306.

39. Sandmaier, B.M., et al., Results of a phase 1 study of quizartinib as maintenance therapy in subjects with acute myeloid leukemia in remission following allogeneic hematopoietic stem cell transplant. Am J Hematol, 2018. 93(2): p. 222-231.

40. Tarlock, K., et al., Sorafenib treatment following hematopoietic stem cell transplant in pediatric FLT3/ITD acute myeloid leukemia. Pediatr Blood Cancer, 2015. 62(6): p. 1048-54.

41. Chen, Y.B., et al., Phase I trial of maintenance sorafenib after allogeneic hematopoietic stem cell transplantation for fms-like tyrosine kinase 3 internal tandem duplication acute myeloid leukemia. Biol Blood Marrow Transplant, 2014. 20(12): p. 2042-8.

42. Maziarz, R.T., et al., Midostaurin after allogeneic stem cell transplant in patients with FLT3-internal tandem duplication-positive acute myeloid leukemia. Bone Marrow Transplant, 2020.

43. Xuan, L., et al., Sorafenib maintenance in patients with FLT3-ITD acute myeloid leukaemia undergoing allogeneic haematopoietic stem-cell transplantation: an open-label, multicentre, randomised phase 3 trial. The lancet. Oncology, 2020. 21(9): p. 1201-1212. 
44. Burchert, A., et al., Sorafenib Maintenance After Allogeneic Hematopoietic Stem Cell Transplantation for Acute Myeloid Leukemia With FLT3-Internal Tandem Duplication Mutation (SORMAIN). J Clin Oncol, 2020. 38(26): p. 2993-3002.

45. Sairah Ahmed, R.S., Gabriela Rondon, Amin Alousi, Qaiser Bashir, Stefan Ciurea, Gheath Al-Atrash, Keyur Patel, Amanda Olson, David Marin, Katy Rezvani, Partow Kebriaei, Uday Popat, Elizabeth Shpall, Richard Champlin, Betul Oran, SORAFENIB MAINTENANCE IN FLT3-ITD MUTATED ACUTE MYELOID LEUKEMIA AFTER ALLOGENEIC STEM CELL TRANSPLANT. 2017.

46. Shi, J., et al., Maintenance sorafenib is superior to prophylactic donor lymphocyte infusion at improving the prognosis of acute myeloid leukemia with FMS-like tyrosine kinase 3 internal tandem duplication after allogeneic hematopoietic stem cell transplantation. Bone Marrow Transplant, 2021. 56(1): p. 293-296.

47. Bazarbachi, A., et al., Sorafenib improves survival of FLT3-mutated acute myeloid leukemia in relapse after allogeneic stem cell transplantation: a report of the EBMT Acute Leukemia Working Party. Haematologica, 2019. 104(9): p. e398-e401.

48. Chappell, G., et al., Maintenance sorafenib in FLT3-ITD AML following allogeneic HCT favorably impacts relapse and overall survival. Bone Marrow Transplant, 2019. 54(9): p. 1518-1520.

49. Bazarbachi, A., et al., FLT3Clinical practice recommendation on hematopoietic stem cell transplantation for acute myeloid leukemia patients with -internal tandem duplication: a position statement from the Acute Leukemia Working Party of the European Society for Blood and Marrow Transplantation. 2020. 105(6): p. 1507-1516.

50. Schlenk, R.F., et al., Midostaurin added to chemotherapy and continued single-agent maintenance therapy in acute myeloid leukemia with FLT3-ITD. Blood, 2019. 133(8): p. 840-851.

51. Bloomfield, C.D., G.P. Herzig, and M.A. Caligiuri, Introduction: acute leukemia: recent advances. Semin Oncol, 1997. 24(1): p. 1-2.

52. Kindler, T., D.B. Lipka, and T. Fischer, FLT3 as a therapeutic target in AML: still challenging after all these years. Blood, 2010. 116(24): p. 5089-102.

\section{Figures}


3438 relevant studies in initial search: PubMed( $n=262)$, Embase ( $n=2893)$, the Cochrane Library $(n=283)$.
0 additional article from protentional references.

309 duplicate studies were deleted.

3129 studies were screened title and abstract.

2970 studies were excluded for following reasons: not relevant to subject( $n=2403)$, in vitro, animal and other non-clinical studies $(n=72)$, other drugs $(n=386)$, other diseases $(n=23)$, case reports $(n=51)$, review $(n=35)$

159 studies were screened full-text.

144 studies were excluded for following reasons: they did not report the primary outcomes of interest.

15 studies were included eventually: 7 prospective studies and 8 retrospective studies.

\section{Figure 1}

Study selection process 
2.1.1 OS

Ahmed 2017

Bazarbachi 2019

$-1.386 \quad 0.654$

$\begin{array}{ll}-1.273 & 0.322\end{array}$

$\begin{array}{ll}-1.347 & 0.564\end{array}$

$\begin{array}{ll}-1.423 & 0.568\end{array}$

$-1.609 \quad 0.516$

Burchert et al. 2020

Chappell 2019

Li et al. 2018

Li et al. 2020

Maziarz et al. 2020

Shi 2020

Subtotal (95\% Cl)

Heterogeneity: $\mathrm{Ch}^{2}=6.17, \mathrm{df}=8(\mathrm{P}=0.63) ; \mathrm{I}^{2}=0 \%$

Test for overall effect: $Z=7.25(P<0.00001)$

\subsubsection{LFS}

\section{Ahmed 2017}

Brunner et al. 2016

Burchert et al. 2020

Li et al. 2018

Li et al. 2020

Maziarz et al. 2020

Shi 2020

Subtotal $(95 \% \mathrm{Cl})$

$-0.755 \quad 0.365$

$-0.734 \quad 0.296$

$\begin{array}{ll}-0.545 & 0.572\end{array}$

$-0.713 \quad 0.301$

Heterogeneity: $\mathrm{Chi}^{2}=1.40, \mathrm{df}=6(\mathrm{P}=0.97) ; \mathrm{I}^{2}=0 \%$

Test for overall effect: $Z=7.34$ ( $P<0.00001)$

\subsubsection{CIR}

Brunner et al. 2016

Burchert et al. 2020

Chappell 2019

Li et al. 2018

Li et al. 2020

Shi 2020

Subtotal (95\% Cl)

Heterogeneity: $\mathrm{Ch}^{2}=1.07, \mathrm{df}=5(\mathrm{P}=0.96) ; \mathrm{I}^{2}=0 \%$

Test for overall effect: $Z=6.46(P<0.00001)$

\subsubsection{NRM}

Brunner et al. 2016

Burchert et al. 2020

Li et al. 2018

Li et al. 2020

Shi 2020

\section{Subtotal $(95 \% \mathrm{Cl})$}

Heterogeneity: $\mathrm{Chi}^{2}=1.30, \mathrm{df}=4(\mathrm{P}=0.86) ; \mathrm{I}^{2}=0 \%$

Test for overall effect: $Z=1.26(P=0.21)$

Test for subaroun differences: $\mathrm{Ch}^{2}=8.65 . \mathrm{df}=3(\mathrm{P}=0.03) . \mathrm{I}^{2}=65.3 \%$
$4.7 \% \quad 0.30[0.08,1.08]$

$6.0 \% \quad 0.25[0.08,0.78]$

$8.9 \% \quad 0.26[0.10,0.65]$

$18.6 \% \quad 0.33[0.17,0.63]$

$28.2 \% \quad 0.37[0.22,0.63]$

$13.2 \% \quad 0.39[0.18,0.84]$

$20.4 \% \quad 0.43[0.23,0.80]$

$100.0 \% \quad 0.35[0.27,0.47]$
$4.3 \% \quad 0.25[0.07,0.90]$

$17.5 \% \quad 0.28[0.15,0.53]$

$5.7 \% \quad 0.26[0.09,0.79]$

$5.6 \% \quad 0.24[0.08,0.73]$

$6.8 \% \quad 0.20[0.07,0.55]$

$13.6 \% \quad 0.47[0.23,0.96]$

$20.8 \% \quad 0.48[0.27,0.86]$

$5.6 \% \quad 0.58[0.19,1.78]$

$20.1 \% \quad 0.49[0.27,0.88]$

$100.0 \% \quad 0.38[0.29,0.49]$

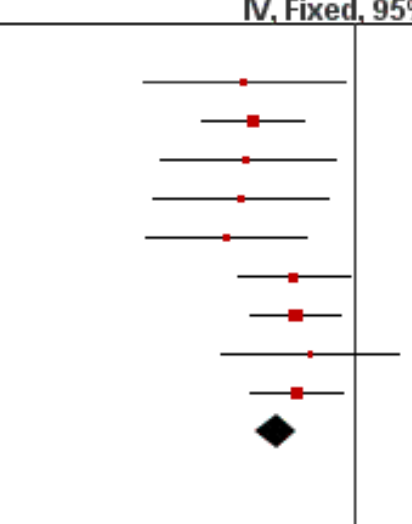

$13.0 \% \quad 0.27[0.10,0.71]$

$19.8 \% \quad 0.39[0.18,0.85]$

$10.1 \% \quad 0.27[0.09,0.80]$

$21.7 \% \quad 0.40[0.19,0.84]$

$26.2 \% \quad 0.29[0.15,0.57]$

$9.2 \% \quad 0.25[0.08,0.78]$

$100.0 \% \quad 0.32[0.23,0.45]$

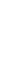

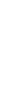




\section{Experimental Control Odds Ratio}

Odds Ratio

Studv or Subgroup Events Total Events Total Weight M-H, Random, 95\% Cl 3.1.1 haematological toxicity

Brunner et al. 201

$\begin{array}{rr}3 & 26 \\ 1 & 43 \\ 15 & 100 \\ 9 & 30 \\ & 199\end{array}$

$12.96[0.64,261.66]$

Burchert et al. 2020

Li et al. 2020

Maziarz et al. 2020

Subtotal $(95 \% \mathrm{Cl})$

199

$0.93[0.06,15.36]$

$2.39[0.93,6.15]$

$0.49[0.17,1.41]$

$1.47[0.43,5.09]$

Total events $28 \quad 22$

Heterogeneity: $\operatorname{Tau}^{2}=0.83 ; \mathrm{Chi}^{2}=7.21, \mathrm{df}=3(\mathrm{P}=0.07) ; \mathrm{I}^{2}=58 \%$

Test for overall effect: $Z=0.61(P=0.54)$

\subsection{2 gastrointestinal toxicity}

$\begin{array}{lrrrrr}\text { Burchert et al. 2020 } & 2 & 43 & 3 & 40 & 21.2 \% \\ \text { Li et al. 2020 } & 11 & 100 & 8 & 102 & 78.8 \% \\ \text { Subtotal }(95 \% \text { Cl) } & & \mathbf{1 4 3} & & \mathbf{1 4 2} & \mathbf{1 0 0 . 0} \%\end{array}$

Total events $13 \quad 11$

Heterogeneity: $\operatorname{Tau}^{2}=0.00 ; \mathrm{Chi}^{2}=0.69, \mathrm{df}=1(\mathrm{P}=0.41) ; \mathrm{I}^{2}=0 \%$

Test for overall effect: $Z=0.43(P=0.67)$

\subsection{3 cadiovascular toxicity}

$\begin{array}{lrrrrr}\text { Burchert et al. 2020 } & 1 & 43 & 0 & 40 & 14.9 \% \\ \text { Li et al. 2020 } & 0 & 100 & 1 & 102 & 15.1 \% \\ \text { Maziarz et al. 2020 } & 6 & 30 & 3 & 30 & 70.0 \% \\ \text { Subtotal (95\% Cl) } & & \mathbf{1 7 3} & & \mathbf{1 7 2} & \mathbf{1 0 0 . 0 \%} \\ \text { Total events } & 7 & & 4 & & \end{array}$

Heterogeneity: $\operatorname{Tau}^{2}=0.00 ; \mathrm{Ch}^{2}=1.21, \mathrm{df}=2(\mathrm{P}=0.54) ; \mathrm{I}^{2}=0 \%$

Test for overall effect: $Z=0.88(P=0.38)$

\subsection{4 cutaneous toxicity}

$\begin{array}{lrrrrrr}\text { Brunner et al. 2016 } & 3 & 26 & 0 & 43 & 14.8 \% & 12.96[0.64,261.66] \\ \text { Burchert et al. 2020 } & 2 & 43 & 1 & 40 & 19.7 \% & 1.90[0.17,21.83] \\ \text { Li et al. 2020 } & 7 & 100 & 1 & 102 & 23.5 \% & 7.60[0.92,62.96] \\ \text { Maziarz et al. 2020 } & 12 & 30 & 13 & 30 & 42.0 \% & 0.87[0.31,2.43] \\ \text { Subtotal (95\% Cl) } & & \mathbf{1 9 9} & & \mathbf{2 1 5} & \mathbf{1 0 0 . 0} \% & \mathbf{2 . 5 2}[\mathbf{0 . 6 5}, \mathbf{9 . 7 1}]\end{array}$

$(95 \% \mathrm{Cl})$

$24 \quad 15$

Heterogeneity: $\mathrm{Tau}^{2}=0.85 ; \mathrm{Chi}^{2}=5.52, \mathrm{df}=3(\mathrm{P}=0.14) ; \mathrm{I}^{2}=46 \%$

Test for overall effect: $Z=1.34(P=0.18)$

\subsection{5 infection}

Burchert et al. 2020

Li et al. 2020

Maziarz et al. 2020

Subtotal $(95 \% \mathrm{Cl})$

Total events

$\begin{array}{rr}1 & 43 \\ 25 & 100 \\ 6 & 30 \\ & \mathbf{1 7 3}\end{array}$

$\begin{array}{rrr}2 & 40 & 5.5 \% \\ 24 & 102 & 79.6 \% \\ 3 & 30 & 14.8 \% \\ & \mathbf{1 7 2} & \mathbf{1 0 0 . 0 \%}\end{array}$

$2.86[0.11,72.23]$

$0.34[0.01,8.36]$

$2.25[0.51,9.99]$

$1.75[0.50,6.10]$

$0.60[0.10,3.80]$

$1.20[0.52,2.81]$

M-H, Random, 95\% Cl

Heterogeneity: $\mathrm{Tau}^{2}=0.00 ; \mathrm{Chi}^{2}=1.37, \mathrm{df}=2(\mathrm{P}=0.50) ; \mathrm{I}^{2}=0 \%$

Test for overall effect: $Z=0.48(P=0.63)$

Test for subaroun differences: $\mathrm{Chi}^{2}=1.37 . \mathrm{df}=4(\mathrm{P}=0.85) . \mathrm{I}^{2}=0 \%$

$0.45[0.04,5.19]$

$1.08[0.57,2.06]$

$2.25[0.51,9.99]$

$1.15[0.65,2.04]$

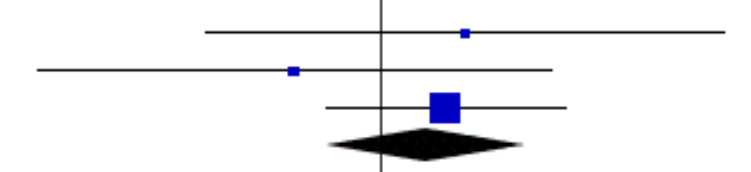

Figure 3

The odds ratio(OR) for the toxicity events. Figure 3.1.1 The OR for hematological toxic effects was $1.47(95 \% \mathrm{Cl}=0.43-5.09, \mathrm{P}=0.54)$; Figure 3.1.2 The OR for gastrointestinal toxicity was $1.20(95 \% \mathrm{Cl} 0.52-$ $2.81, \mathrm{P}=0.67)$; Figure 3.1.3 The OR for cardiovascular toxicity was $1.75(95 \% \mathrm{Cl} 0.50-6.10, \mathrm{P}=0.38)$; Figure 3.1.4 The OR for cutaneous toxicity was $2.52(95 \% \mathrm{Cl} 0.65-9.71, \mathrm{P}=0.18)$; Figure 3.1.5 The OR for infectious toxicity was $1.15(95 \% \mathrm{Cl} 0.65-2.04, \mathrm{P}=0.63)$. 


\subsection{1 aGVHD}

Brunner et al. 2016

Burchert et al. 2020

Li et al. 2020

Maziarz et al. 2020

Shi 2020

Subtotal $(95 \% \mathrm{Cl})$

Total events

Heterogeneity: $\mathrm{Ch}^{2}=3.76, \mathrm{df}=4(\mathrm{P}=0.44) ; \mathrm{I}^{2}=0 \%$

Test for overall effect: $Z=0.02(P=0.99)$

\subsection{2 cGVHD}

Brunner et al. 2016

Burchert et al. 2020

Li et al. 2020

Maziarz et al. 2020

Shi 2020

Subtotal $(95 \% \mathrm{Cl})$

Total events

$\begin{array}{rrrrr}1 & 26 & 6 & 43 & 10.8 \% \\ 10 & 43 & 7 & 40 & 13.8 \% \\ 23 & 100 & 21 & 102 & 39.7 \% \\ 8 & 30 & 12 & 30 & 21.8 \% \\ 11 & 24 & 12 & 32 & 13.8 \% \\ & 223 & & \mathbf{2 4 7} & \mathbf{1 0 0 . 0} \%\end{array}$

$0.25[0.03,2.18]$

$1.43[0.49,4.21]$

$1.15[0.59,2.25]$

$0.55[0.18,1.62]$

$1.41[0.48,4.13]$

$1.00[0.64,1.54]$ 58

Heterogeneity: $\mathrm{Chi}^{2}=3.45, \mathrm{df}=4(\mathrm{P}=0.49) ; \mathrm{I}^{2}=0 \%$

Test for overall effect: $Z=1.25(P=0.21)$

Test for subaroun differences: $\mathrm{Chi}^{2}=0.76 . \mathrm{df}=1(\mathrm{P}=0.38) . \mathrm{I}^{\mathrm{z}}=0 \%$
$2.30[0.85,6.22]$

$1.87[0.78,4.47]$

$1.10[0.53,2.28]$

$0.86[0.29,2.55]$

$0.79[0.25,2.47]$

$1.30[0.86,1.96]$

\section{2}

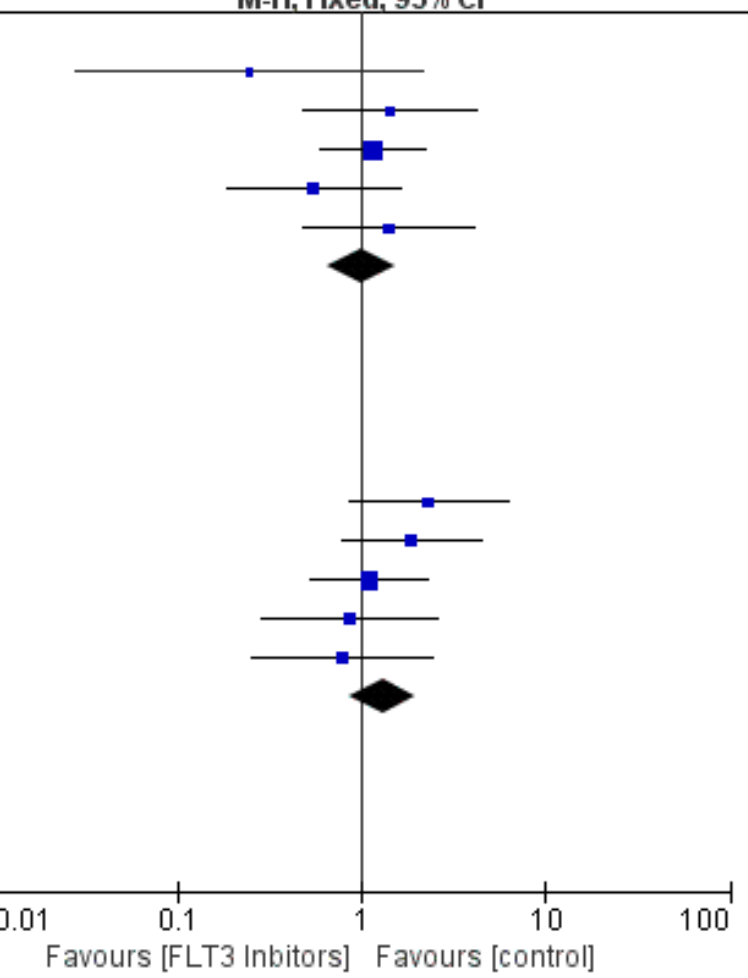

\section{Figure 4}

The odds ratio(OR) for the GVHD events. Figure 4.1.1 The OR for aGVHD events was $1.00(95 \% \mathrm{Cl}=0.64-$ 1.54, $\mathrm{P}=0.99)$; Figure 4.1.2 The OR for $\mathrm{CGVHD}$ events was $1.30(95 \% \mathrm{Cl}=0.86-1.96, \mathrm{P}=0.21)$. 


$\begin{array}{lrrrr}\text { 5.1.1 MRD+ before transplantation } & & & \\ \text { Burchert et al. 2020 } & -0.41552 & 0.380935 & 17.3 \% & 0.66[0.31,1.39] \\ \text { Li et al. 2020 } & -1.10866 & 0.441426 & 14.1 \% & 0.33[0.14,0.78] \\ \text { Subtotal (95\% Cl) } & & & \mathbf{3 1 . 4} \% & \mathbf{0 . 4 8}[\mathbf{0 . 2 5}, \mathbf{0 . 9 5}]\end{array}$

Heterogeneity: Tau $^{2}=0.07 ; \mathrm{Chi}^{2}=1.41, \mathrm{df}=1(\mathrm{P}=0.23) ; \mathrm{I}^{2}=29 \%$

Test for overall effect: $Z=2.11(P=0.04)$

\subsubsection{MRD- before transplantation}

$\begin{array}{lrrrr}\text { Burchert et al. 2020 } & -1.34707 & 0.608792 & 8.5 \% & 0.26[0.08,0.86] \\ \text { Li et al. 2020 } & -1.56065 & 0.564534 & 9.6 \% & 0.21[0.07,0.63] \\ \text { Subtotal }(\mathbf{9 5 \%} \text { Cl) } & & & \mathbf{1 8 . 1} \% & \mathbf{0 . 2 3}[\mathbf{0 . 1 0}, \mathbf{0 . 5 2}]\end{array}$

Heterogeneity: Tau $^{2}=0.00 ; \mathrm{Ch}^{2}=0.07, \mathrm{df}=1(\mathrm{P}=0.80) ; \mathrm{I}^{2}=0 \%$

Test for overall effect: $Z=3.53(\mathrm{P}=0.0004)$

\subsubsection{MRD+ after transplantation}

$\begin{array}{lrrrr}\text { Burchert et al. 2020 } & -1.96611 & 0.796147 & 5.3 \% & 0.14[0.03,0.67] \\ \text { Li et al. 2020 } & -1.38629 & 0.701922 & 6.7 \% & 0.25[0.06,0.99] \\ \text { Subtotal }(\mathbf{9 5 \%} \text { Cl) } & & & \mathbf{1 2 . 0 \%} & \mathbf{0 . 1 9}[\mathbf{0 . 0 7}, \mathbf{0 . 5 4}]\end{array}$

Heterogeneity: $\operatorname{Tau}^{2}=0.00 ; \mathrm{Chi}^{2}=0.30, \mathrm{df}=1(P=0.58) ; \mathrm{I}^{2}=0 \%$

Test for overall effect: $Z=3.11(P=0.002)$

\subsubsection{MRD- after transplantation}

$\begin{array}{lrrrr}\text { Burchert et al. 2020 } & -0.41552 & 0.313435 & 22.1 \% & 0.66[0.36,1.22] \\ \text { Li et al. 2020 } & -1.27297 & 0.398517 & 16.3 \% & 0.28[0.13,0.61] \\ \text { Subtotal (95\% Cl) } & & & \mathbf{3 8 . 4} \% & \mathbf{0 . 4 5}[\mathbf{0 . 1 9}, \mathbf{1 . 0 3}]\end{array}$

Heterogeneity: $\operatorname{Tau}^{2}=0.24 ; \mathrm{Chi}^{2}=2.86, \mathrm{df}=1(\mathrm{P}=0.09) ; \mathrm{I}^{2}=65 \%$

Test for overall effect: $Z=1.89(P=0.06)$

Total $(95 \% \mathrm{Cl}) \quad 100.0 \%$

Heterogeneity: $\mathrm{Tau}^{2}=0.07 ; \mathrm{Chi}^{2}=9.26, \mathrm{df}=7(\mathrm{P}=0.23) ; \mathrm{I}^{2}=24 \%$

Test for overall effect: $Z=5.11$ ( $P<0.00001)$

Test for subaroun differences: $\mathrm{Chi}^{2}=3.44 . \mathrm{df}=3(\mathrm{P}=0.33) . \mathrm{I}^{2}=12.7 \%$

$0.37[0.25,0.54]$

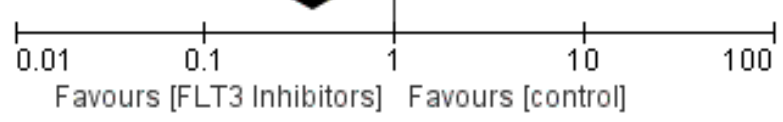

\section{Figure 5}

The subgroup analysis for the MRD negative or positive before or after HSCT. Figure 5.1.1 The HR for MRD positive before HSCT. was 0.48 (95\% $\mathrm{Cl}=0.25-0.95, \mathrm{P}=0.04)$; Figure 5.1.2 The HR for MRD negative before HSCT. was $0.23(95 \% \mathrm{Cl}=0.10-0.52, \mathrm{P}=0.004)$; Figure 5.1.3 The HR for MRD positive after HSCT. was $0.19(95 \% \mathrm{Cl}=0.07-0.54, \mathrm{P}=0.002)$; Figure 5.1.4 The HR for MRD negative after HSCT was 0.45 (95\% $\mathrm{Cl}=0.19-1.03, \mathrm{P}=0.06)$.

\section{Supplementary Files}

This is a list of supplementary files associated with this preprint. Click to download.

- supplementalmaterial.docx 